\title{
Identifying agents of change for sustainable land governance
}

\author{
O. Ravaka Andriamihaja ${ }^{\mathrm{a}, \mathrm{b}, *}$, Florence Metz ${ }^{\mathrm{c}, \mathrm{d}}$, Julie G. Zaehringer ${ }^{\mathrm{a}}$, Manuel Fischer ${ }^{\mathrm{c}, \mathrm{e}}$, \\ Peter Messerli ${ }^{\mathrm{b}, \mathrm{f}}$ \\ ${ }^{\text {a }}$ Centre for Development and Environment, University of Bern, Mittelstrasse 43, CH-3012 Bern, Switzerland \\ ${ }^{\mathrm{b}}$ Institute of Geography, University of Bern, Hallerstrasse 12, CH-3012 Bern, Switzerland \\ ${ }^{\mathrm{c}}$ Institute of Political Science, University of Bern, Fabrikstrasse 8, CH-3012 Bern, Switzerland \\ ${ }^{\mathrm{d}}$ Department of Governance \& Technology for Sustainability, University of Twente, Drienerlolaan 5, NL-7522 NB Enschede, The Netherlands \\ ${ }^{\mathrm{e}}$ Department of Environmental Social Sciences, Eawag (Swiss Federal Institute of Aquatic Science and Technology), Überlandstrasse 133, CH-8600 Dübendorf, Switzerland \\ ${ }^{\mathrm{f}}$ The Wyss Academy for Nature, University of Bern, Mittelstrasse 43, CH-3012 Bern, Switzerland
}

\section{A R T I C L E I N F O}

\section{Keywords:}

Agents of change

Telecoupled land governance

Sustainability transformation

Agency analysis

Social network analysis

Madagascar

\begin{abstract}
A B S T R A C T
Sustainable land governance in a telecoupled world is currently a challenge. Distant actors, institutions, and interactions shape local land uses and are assumed to affect sustainable development in critical ways as they exert new and often additional claims on land and trigger adverse local impacts like displacement. Action towards achieving the Sustainable Development Goals (SDGs) is urgently needed, as are agents of change that will initiate sustainability transformations. However, empirical studies on transformation pathways towards sustainable land governance remain scarce. Moreover, very few studies have addressed the identification of actors through whom such transformation might be achieved. To address this gap, we analysed the likelihood of actors becoming agents of change based on their aims, resources, and relational profiles in the land governance network. Our study focused on Madagascar, a country that manifests unsustainable land governance, with distant actors increasingly influencing local land use. We combined an analysis of agency with social network analysis to disentangle attributes and the transformative potential of different actors involved in land governance in northeastern Madagascar. Our results show that actors have different combinations of aims, resources, and relational profiles. Combined analysis of their agency and social networks enabled us to identify potential agents of change and yielded options for transformation actions through which they can become operational agents of change. Our research contributes to promoting pathways to sustainability transformations where actors with various agency levels and social network assets are empowered to establish sustainable land governance. The combination of agency analysis and social network analysis is an innovative method that helps to advance sustainability science.
\end{abstract}

\section{Introduction}

An increasingly telecoupled world (Liu et al., 2013) facilitates international trade (Lambin and Meyfroidt, 2011), information, and technology flows (Papworth et al., 2015) and farmers' access to global markets (Carrasco et al., 2017; Galaz et al., 2015). However, this connectivity also drives different socio-economic and environmental problems, such as climate change, inequality, biodiversity loss, and issues of environmental justice (Barlow et al., 2016; Brockington and Wilkie, 2015; Corbera et al., 2019; Stevens-Rumann et al., 2018). To address these problems, in 2015 the United Nations adopted the 2030 Agenda for Sustainable Development. Titled "Transforming our world", it set down 17 integrated and indivisible Sustainable Development Goals (SDGs) with 169 targets, to be reached by 2030 .

Land is at the heart of the challenges facing our telecoupled world. Actors at different scales may exhibit different priorities regarding the functions and benefits of land, leading to land use sustainability tradeoffs (Zaehringer et al., 2019). Trade-offs occur when the achievement of one SDG in one social-ecological system undermines the achievement of another SDG in the same or in another social-ecological system (Nilsson et al., 2018). Put differently, the sustainability of land use in one socialecological system is influenced by other, distant social-ecological systems (Challies et al., 2019). Examples of such interdependences include displacement, leakage, conservation off-setting, and lifestyle choices

\footnotetext{
* Corresponding author at: Centre for Development and Environment, University of Bern, Mittelstrasse 43, CH-3012 Bern, Switzerland.

E-mail addresses: ravaka.andriamihaja@cde.unibe.ch (O.R. Andriamihaja), florence.metz@ipw.unibe.ch (F. Metz), julie.zaehringer@cde.unibe.ch (J.G. Zaehringer), Manuel.Fischer@eawag.ch (M. Fischer), peter.messerli@cde.unibe.ch (P. Messerli).
} 
(Lambin and Meyfroidt, 2011; Meyfroidt et al., 2018). Under telecoupling, land is revalorized by distant demands (Eakin et al., 2014; Liu et al., 2013), giving rise to sustainability challenges such as unsustainable production practices and lack of waste management (Garrett and Rueda, 2019; Godar and Gardner, 2019; Haberl et al., 2015). The key role of land in sustainable development suggests that one important avenue for addressing sustainability transformations is through sustainable land governance (Verburg et al., 2015; Westley et al., 2011).

Transformation implies a fundamental and significant systemic change of existing structures and systems into new ones (Abson et al., 2017; Blythe et al., 2018; Dentoni et al., 2017; Pelling, 2014; Westley et al., 2013). The dynamics of current global challenges like climate change, growing inequality, or biodiversity loss underline the urgency of achieving transformational changes (Secretary-General, U.N., 2019). Our research looks at ways of transforming current telecoupled land governance, which is leading to increasingly unequal land competition (Andriamihaja et al., 2019), into sustainable telecoupled land governance. This requires the identification of transformation actors (Blythe et al., 2018) that have the power to initiate negotiation and collective decision-making among different types of actors (Munroe et al., 2019) and to balance trade-offs, for example between conservation and development. Various strands of literature have labelled these actors "institutional entrepreneurs" (Duygan et al., 2019; Westley et al., 2013), "policy entrepreneurs" (Aviram et al., 2020; Mintrom and Norman, 2009), "central (key) actors" (Bodin and Crona, 2009; Mbaru and Barnes, 2017), "agents of change" (Lampert and Mohan, 2018), or "agents of transformation" (Clarke, 2007). Empirical studies have examined transformation pathways towards adaptive governance and sustainable development (Braun, 2015; Pelling, 2014; Roggema et al., 2012; van Vuuren et al., 2012). While very few studies have addressed the identification of individual and organizational actors, we make an important contribution to the literature with a conceptualization and methodology for the identification of what we refer to as agents of change. Agents of change are central to the study of sustainable land governance as they represent the actors through whom the necessary transformation actions might be achieved. In order to identify such crucial agents of change, studies have focused separately on either agency or structural perspectives: for example, Westley et al. (2013) used agency analysis, while Mbaru and Barnes (2017) used social network analysis. We propose an innovative methodology that combines both methods and thereby identifies change agents in a particularly reliable way (the only similar approach, to our knowledge, is the study by Duygan et al. (2019)).

Madagascar is experiencing major sustainability issues. In the northeastern part of the country, international NGOs are working to implement a global conservation agenda to protect the remaining tropical forest (Bertrand et al., 2014; Gardner et al., 2018; Neudert et al., 2017). At the same time, small-scale farmers cultivate cash crops such as cloves and vanilla to supply a global agricultural commodity market (Andriamihaja et al., 2019; Neimark et al., 2019; Zhu, 2018). Conservation and economic development constitute distant incentives for different land uses in the same landscapes, driving increasing land competition. The latter results in conflicts around deforestation, inequality, and environmental justice (Andriamihaja et al., 2019; Boillat et al., 2018; Neudert et al., 2017; Zaehringer et al., 2016). Achieving a just balance between the production and conservation functions of land use and contributing to achieving the SDGs requires sustainable forms of telecoupled land governance that support transformation action (Andriamihaja et al., 2019; Schneider et al., 2019; Westley et al., 2013; Zaehringer et al., 2019).

Such action may consist, for example, in extra funding to compensate poor local people for bearing the cost of forest conservation and to ensure that forest conservation contributes to achieving sustainable development (Poudyal et al., 2018). Andriamihaja et al. (2019) suggest connecting actors from different sectors and levels of the land governance network. Gardner et al. (2018) point out the importance of paying equal attention to protected area effectiveness and protected area coverage. Neimark et al. (2019) recommend sustainability interventions that address complex issues like security and transparent land governance. In all these examples, it is crucial that transformational change is identified as desirable in a knowledge-based process (Blythe et al., 2018). Furthermore, it is key to identify the actors that will lead these transformation actions.

In our study, we tested an innovative approach combining agency analysis and social network analysis to identify potential agents of change. This appeared promising with regard to advancing research in the fields of both transformation and sustainable land governance. Our main question was: How can we identify potential agents of change within telecoupled land governance in northeastern Madagascar? Following the introduction, this paper presents our theoretical framework, in which we conceptualize agents of change in an innovative way. We then describe our case study landscapes and the methods we applied. Our analysis comprises three steps: First, we characterized actors involved in land governance in northeastern Madagascar in terms of their aims, resources, and social networks. Second, we combined these three components in a principal component analysis. Third, we established a typology of potential agents of change for the transformation of land governance. Finally, in addition to this empirical advancement regarding the identification of potential change agents in telecoupled land governance, we developed recommendations for potential transformation actions.

\section{Conceptual framework: agents of change for sustainable land governance}

Transformative action to tackle the social, economic, and environmental problems the world is facing - such as insecurity, inequality, and climate change - requires agents of change to perform it. In this study, we took up the challenge of combining agency analysis and social network analysis to identify such agents of change. As our study relates to land governance, we aimed, more specifically, to find agents of change towards sustainable land governance among the organizational actors who were already part of the current land governance network.

As a conceptual basis for our study we chose a human actor model (Wiesmann et al., 2011). This model defines actors by their action, which is the sum of their meanings (the strategies motivating actors to perform an action), their means (the resources through which actors achieve a meaning and implement an action), and their activity (interactions with other actors while implementing an action). Fig. 1 summarizes our conceptual framework. In it, we conceptualize actors' agency as the combination of their meaning, represented by their aims, and their means, represented by their resources. Further, we understand actors' interactions as the flows that emerge between actors as they send and receive goods, money, and information related to land use. These flows form ties between actors. The ensemble of an actor's ties then represents the actor's social network and defines the actor's network position (Bodin and Crona, 2009; Borgatti et al., 2009; Isaac and Matous, 2017) in terms of its centrality. In this conceptualization, actors must act and use their resources and social networks to achieve their aims and contribute to sustainability.

In our case, actors' aims or meanings represent their values and visions regarding sustainable land governance, and their resources or means represent their capabilities to transform current governance practices into sustainable ones. Actors' centrality enables them to reach, connect, bridge, and influence different actors from similar or different sectors, domains, and levels. Any analysis and categorization of agents of change should consider both actors' agency and their social networks.

But what is an ideal agent of change towards sustainable land governance? We defined this as an actor who has: (1) sustainability aims, 


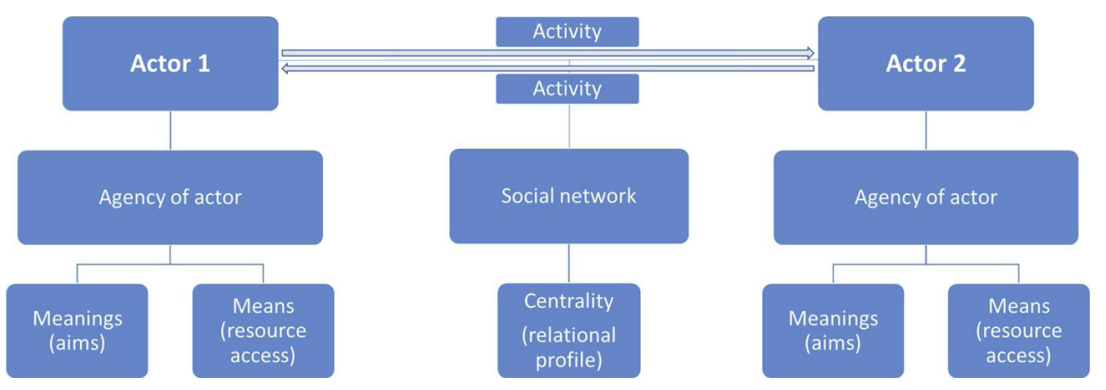

Fig. 1. Conceptual framework for analysing agents of change.

with respect to all three dimensions of sustainable development - the social, the economic, and the environmental (Challies et al., 2019); (2) a rich and diverse set of resources to implement transformation actions (Westley et al., 2011); and (3) a central position to ensure connectivity and influence (Ingold et al., 2018). We regard mixed social, economic, and environmental aims as sustainability aims because an actor with such aims would be aware of different and divergent claims on land. Therefore, actors with mixed aims would be more receptive to environmental claims from conservation actors, socio-economic claims from state actors and traditional authorities, and economic claims from private-sector actors. This actor's resources and relational profile represent the means to implement the actor's sustainability (i.e. mixed) aims. Furthermore, we identify ideal agents of change as the actors with the highest potential for being agents of change, regardless of how likely they are to actually use that potential. Actors who do not fulfil our criteria may become successful agents of change if they are able to adjust their aims or to mobilize the necessary resources and social networks through other actors - which in itself constitutes a transformation action and will enable them to take further transformation action (Westley et al., 2013).

\section{Case study landscapes}

We opted for a case study approach to illustrate this new method of identifying agents of change. We empirically investigated actors of the land governance networks in two case study landscapes in Maroantsetra District, in Analanjirofo Region, northeastern Madagascar. The two case study landscapes are located in two different municipalities - Morafeno and Mahalevona. - and each encompass the municipality's main village and its land (Fig. 2). These villages are home to small-scale cash crop producers working their land, as well as to biodiversity-rich humid tropical forest managed by international conservation NGOs on behalf of the state. Vanilla and clove production as well as conservation activities trigger flows of goods, money, and information along value chains and the conservation network. These flows are exchanged and regulated within the land governance network (Andriamihaja et al., 2019; Gardner et al., 2018; Waeber et al., 2016). Cash crop production and biodiversity conservation - the two land uses attracting the most international actors and representing high financial values - have created competition over land that continues to characterize land governance (Andriamihaja et al., 2019). Although smallholder farmers have gained more power thanks to the growing vanilla price, their future livelihoods might be jeopardized, as sudden access to money in society influences casual interpersonal relationships and dynamics (Neimark et al., 2019): As money becomes available, everything suddenly has a price, and social networks are somewhat neglected. Furthermore, the strong dominance of external actors over local resources raises concerns about environmental injustices (Boillat et al., 2018; Keller, 2015).

The villages' land governance networks and the actors composing them were identified by following the flows of goods, money, and information, as proposed by Andriamihaja et al. (2019). The networks are divided into two domains, one focusing on the environment and the other on the economy. Moreover, its actors belong to either the public, the private, or the voluntary sectors. They are active at different levels, from the local village level to the international level. Finally, these actors have different aims and values with respect to land and their activities, as well as access to different resources to achieve these aims.

The wide range of actors with different attributes who are driving land governance issues makes the selected landscapes ideal cases for the identification of agents of change for sustainability transformation in northeastern Madagascar. The next section explains how we operationalized our conceptual framework for analysing agents of change applying a telecoupling lens to shed light on actors' likelihood to act towards sustainable transformation.

\section{Materials and methods}

\subsection{Focus groups and actor survey}

Data were collected between April 2016 and March 2019 and included two focus group interviews in each village, an actor survey, and secondary data collection (see Andriamihaja et al., 2019 for details). Using snowball sampling, we inventoried a total of 103 actors related to the two case study landscapes' land governance networks. This involved an actor survey of 42 actors and secondary data collection from the internet (their website or blog articles) on 20 other actors. For instance, the website of the World Bank provides their mission statement that we considered as their aim. For flow data, we scanned the relevant documents for actors' collaborations and partnerships and the nature of these links to other actors. For this study, we used the data from 62 actors in total ( $\sim 60 \%$ of the entire set of relevant actors). Another 41 actors were mentioned in the survey or secondary data, but we were unable to obtain more information about them. These correspond to missing data in our set of actors and mostly stem from the district (19), national (9) and international (6) levels. We decided to consider the networks of actors and flows related to the two case study landscapes as one overall network. This ensured that we had a maximum of actors and their social networks to analyse; and furthermore, the two networks converged into the same actors from the district level upwards.

\subsection{Data analysis}

Based on our conceptual framework, our data analysis focused on analysing actors' agency and social networks. We wanted to know whether actors (1) had aims that involve the three dimensions of sustainable development, namely society, the economy, and the environment; (2) had access to relevant resources; and (3) were embedded in a social network in a way that enabled them to achieve their aims. Agency analysis considers the meanings (or aims) and the means (or resources) characterizing actors' activities (Wiesmann et al., 2011). Social network analysis is a suitable methodological approach for disentangling interactions (Bodin and Crona, 2009; Fischer et al., 2017; Seaquist et al., 2014) and dynamics (Aviram et al., 2020; Duygan et al., 2019; Isaac and Matous, 2017) between actors in their land-related activities. To obtain a detailed picture of the actors composing our 


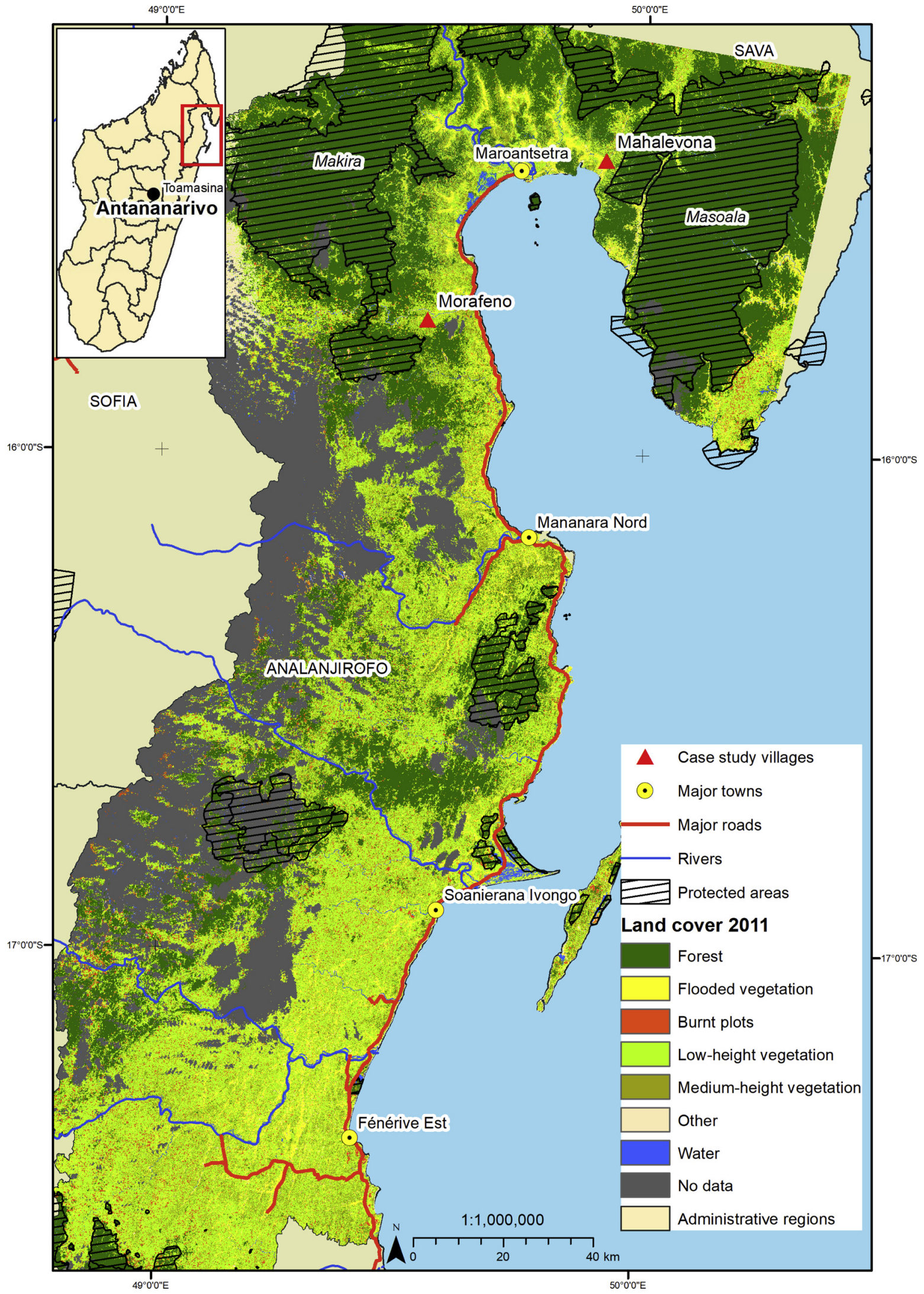

Fig. 2. Location of case study landscapes in Analanjirofo Region, northeastern Madagascar. 
study landscapes' land governance network, we first conducted the two analyses separately. Then we combined the analytical components from both analyses - actors' aims, their resources, and their social network as a basis for categorizing actors into different categories of potential agents of change. In the following subsections, we explain our methods using a fictitious Actor A as an example.

\subsection{Agency analysis}

Agency analysis (Wiesmann et al., 2011) comprises the analysis of actors' meanings (aims) and means (resources). We had survey data for both of these actor attributes. We had asked respondents to indicate the aims of their land-related activities and state the resources they have access to.

The original survey question concerning aims read as follows:

"What is the overall aim of your organization that guides its activities? Please briefly describe the aim of your organization and explain the reason."

To analyse actors' aims, we coded the overall aims of every organizational actor surveyed according to three categories:

(1) Social aims (related to education, nutrition, family, future generations, ...)

(2) Economic aims (related to trade, materials and income, ...)

(3) Environmental aims (related to conservation, environmental pressures, land, ...)

Coding work consisted of identifying concepts (phrases) that relate to a particular aim category (see Appendix for codebook (in Supplementary material)). These concepts were first prepared by the first author, and then were discussed and agreed by all co-authors. The strength of each aim category for a given actor was then expressed as the percentage of all of the actor's concepts belonging to this category compared to the actor's total number of concepts from all three categories. In other words, the strength of each aim category per actor corresponds to the percentage of identified concepts belonging to that category. Fig. 3 shows the fictitious example of Actor A, whose stated aim includes two concepts from the social category and one from the economic category. Accordingly, this actor has a value of $67 \%$ for social aims and $33 \%$ for economic aims - and $0 \%$ for environmental aims. This procedure enabled us to assess each actor's inclination towards each category of aims.

The second attribute of interest in agency analysis is actors' resources. The original question in the survey in this regard was:

"The following table summarizes different types of resources. Which resources does your organization have access to for the achievement of your goals? Please check each resource your organization has access to and characterize it."

To analyse actors' means, we categorized their resources as follows:

(1) Physical resources (transport means, energy/electricity, communication means, production equipment)

(2) Natural resources (land, forest, cash crops, subsistence crops, animals)

\begin{tabular}{|c|c|c|c|c|}
\hline & Aims as expressed by actor & Social aims & Economic aims & Environmental aims \\
\hline \multirow[t]{4}{*}{ Actor A } & I would like to have a nice & \multirow{4}{*}{67} & \multirow{4}{*}{33} & \multirow{4}{*}{0} \\
\hline & house and have enough & & & \\
\hline & money to send my children & & & \\
\hline & to school & & & \\
\hline
\end{tabular}

Fig. 3. Example of coding of aims for Actor A.
(3) Human resources (regular and seasonal employees)

(4) Financial resources (funding, budget, credits)

First, we attributed a score to each resource for each actor according to a common set of criteria (see Table A.1 in Appendix (in Supplementary material)). These scores were then summed up to obtain the total score per resource category for each actor, which in turn we translated into a percentage based on the maximum resource an actor in the sample can have in each category. $25 \%$ is the maximum total score per resource category held by an actor in the sample; accordingly, the total resource score per actor cannot exceed $100 \%$. Second, we divided the actors into two groups based on the median of the total resource scores: those with access to more resources (above the median) and those with access to fewer resources (below the median). Within these groups, we then conducted a hierarchical cluster analysis in $\mathrm{R}$ version 3.5.3 (R Core Team, 2017) using the "factorextra" package version 1.0.5 (Le and Josse, 2020) and including the resource categories above as variables. This enabled us to categorize actors according to the quantity and combination of resources they have access to. However, we normalized and summed up the total score per resource category in order to obtain the total resource score of every actor and feed the typology into the combined analysis of actors' agency and social networks (see below) (Table 1).

\subsection{Social network analysis}

In the survey, we also gathered relational data reflecting the exchange of flows of goods, money, and information between actors related to the two case study landscapes. The original survey question was:

"Related to your activities in Maroantsetra, we would like to understand how you interact with other organizations. These interactions can comprise the exchange of items such as goods, financial capital, or information. Please indicate the item you exchanged. If you received it, from whom? If you provided it, to whom (name and contact)?"

If Actor A indicated sending goods to Actor B, we coded a flow of goods from Actor A to Actor B. We assessed actors' relational profiles using specific social network analysis tools (Freeman, 1978; Wasserman and Faust, 1994). We considered all three types of interactions - involving finances, information, and goods - and aggregated them into a single undirected and weighted network. We consider degree centrality as a basic, general capacity of networking. However, with our conceptual framework focusing on actors' resources for working towards more sustainable land use, we would like to emphasize the importance of actors' relations to other sectors and levels. Both types of bridging capacities thus give more weight to actors' relations to other sectors and levels. Therefore, we calculated actors' degree centrality as well as their bridging capacities across sectors and levels. Actors' degree centrality is calculated as the simple count of the number of interactions of that actor (Freeman 1979), combining in- and out-degree. The bridging capacity across sectors is an actor's capacity to reach actors from a different sector; the bridging capacity across levels is the capacity of an actor to reach actors from a different level. We consider the bridging capacities to be a variant of degree centrality. To determine an actor's bridging capacities, we counted the number of actors from a different sector or level to which that actor is connected. Fig. 4 shows a model of Actor A, who is from the village level and is connected to two actors from the international level, two from the national level, two from the regional level, and two from the district level. Among these, four each are from the public and four from the voluntary sector, while Actor A is from the private sector. Accordingly, Actor A has a degree centrality of 8 , a bridging capacity across levels of 8 ( 2 international +2 national + 2 regional +2 district), and a bridging capacity across sectors of 8 ( 4 public +4 voluntary). Additional connections of Actor A to actors from the village level would not affect Actor A's bridging capacity across 
Table 1

Example of coding of resources for Actor A.

\begin{tabular}{|c|c|c|c|c|c|}
\hline & Natural resources & Human resources & Physical resources & Financial resources & Total for all categories \\
\hline Scores of Actor A & 20 & 5 & 12 & 7 & 44 \\
\hline Maximum scores achieved by an actor in the sample & 20 & 10 & 18 & 10 & \\
\hline Actor A's total score per category (\%) & 25 & 12.5 & 16.66 & 17.5 & 71.16 \\
\hline
\end{tabular}

levels, but they would certainly increase Actor A's degree centrality, and they might increase the bridging capacity across sectors, depending on what sectors the actors are from. Finally, we normalized and summed up the scores of degree centrality, bridging capacity across sectors, and bridging capacity across levels for each actor in order to obtain their total relational profile score. This we then fed into the combined analysis as described below. High scoring at the three relational profile scores (degree centrality and bridging capacities across sector and level) captures the capacity of an actor to reach a high number of actors as well as to reach a high diversity of actors. This diversity represents the pathways towards sustainable land governance.

\subsection{Combined analysis}

We combined the variables from the agency analysis and the social network analysis in two ways. First, we conducted a principal component analysis with the variables corresponding to the categories of the components: social aims, economic aims, environmental aims, natural resources, human resources, physical resources, financial resources, degree centrality, bridging capacity across levels, and bridging capacity across sectors. A principal component analysis (Wallis, 2006; Wold et al., 1987) helps us to detect general patterns in our data with respect to how different types of components (aims, resources and relational profile) combine, and thus to simplify our interpretation of potential agents of change. We performed this analysis using the actors' different scores explained in the preceding paragraphs. Second, we established an actor typology according to the three components and based on the following values:

- Aims, using actors' inclination towards each category
- Resources, using actors' total resource scores

- Relational profile, using actors' total relational profile scores

\section{Results and discussion}

\subsection{Actors' aims}

Fig. 5 shows a ternary diagram of actors based on their aims. In line with our conceptual framework and our conceptualization of an ideal agent of change, we can distinguish four categories of actors: (1) actors with mainly social aims, (2) actors with mainly economic aims, (3) actors with mainly environmental aims, and (4) actors with mixed aims.

The four groups are populated by actors from different sectors and levels. The first group (labelled a in Fig. 5) comprises thirteen actors whose aims focus on social aspects. One example of such an actor in our sample is a local rock crystal intermediary who aims to build a house and send their children to school in the district capital. Actors in this group are mostly public-sector actors from the village, national, and international levels.

The second group (labelled b in Fig. 5) is composed of ten actors whose aims focus mainly on economic development. One example of such an actor is a local cash crop intermediary who aims to generate money to reinvest in their business. Group b is populated mostly by private-sector actors from all five levels, but predominantly from the village, district, and international levels.

The third group (labelled $\mathrm{c}$ in Fig. 5) comprises twelve actors focusing mainly on environmental aims. They are from the public and voluntary sectors and from all levels except the village level. One example is the district-level forestry department that aims to reduce deforestation for expanding clove plantations.

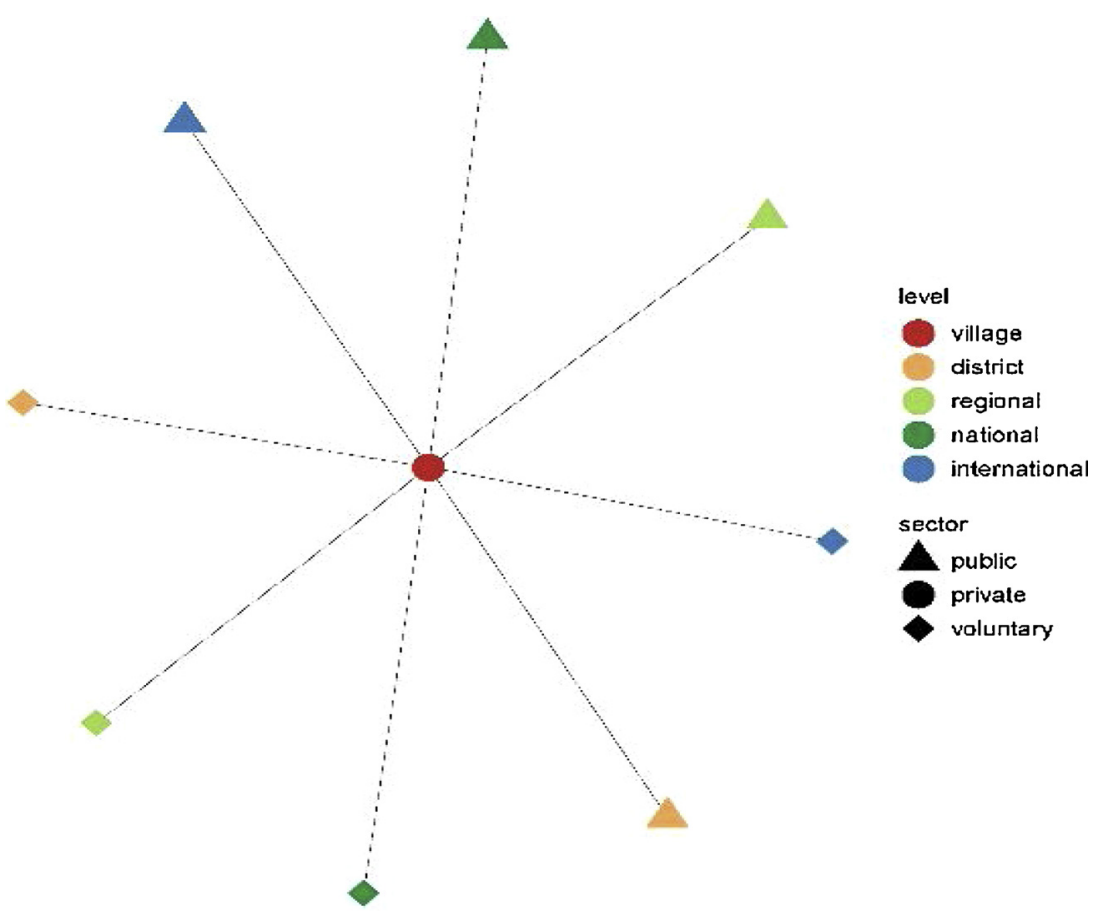

Fig. 4. Model of Actor A with high bridging capacity across sectors and levels. 


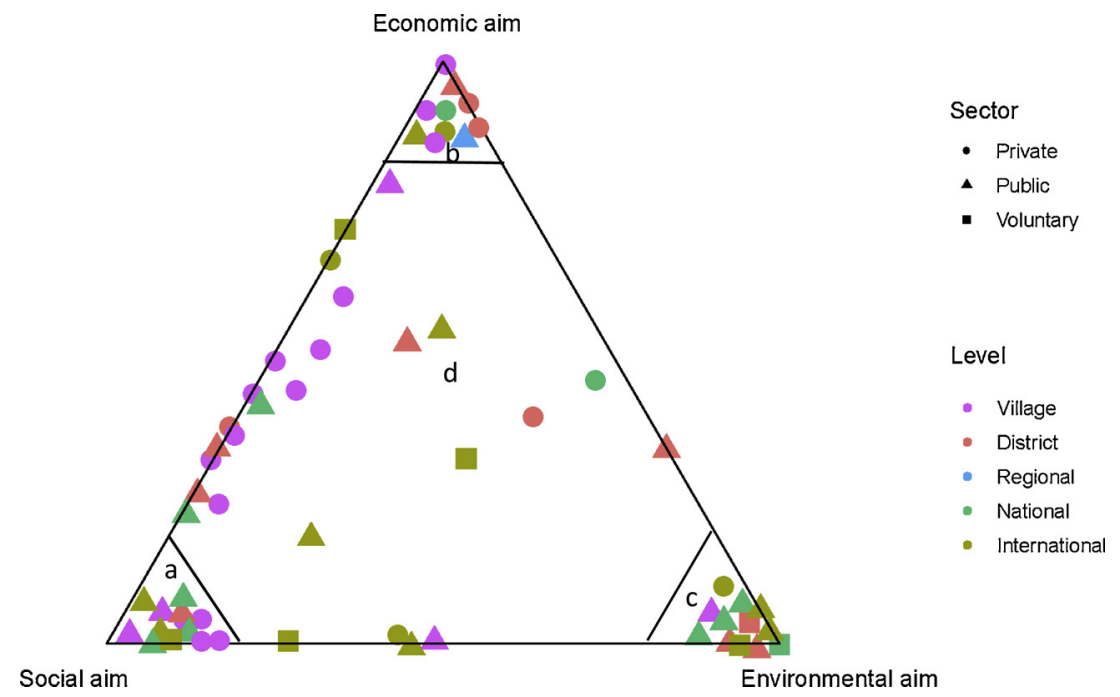

Fig. 5. Ternary diagram of actors from different levels and sectors based on their social, economic, and environmental aims.

The last group (labelled d in Fig. 5 is composed of 27 actors with mixed aims from two or three aim categories. They appear inside and along the sides of the ternary diagram. One such actor is a communitybased natural resource management (CBNRM) group that aims to achieve benefits from conservation for the local population and to assist the NGOs in charge of protected area management in their tasks. Group $\mathrm{d}$ is made up mostly of private- and public-sector actors. Among them, village-level and private-sector actors mostly have a mix of social and economic aims. International actors mostly have a mix of aims from all three categories, of social and economic aims, or of social and environmental aims; none of them combines economic and environmental aims without social aims. District-level actors mostly have a mix of aims from all three categories, of social and economic aims, or of economic and environmental aims.

\subsection{Actors' resources}

Looking at access to resources, the surveyed actors are highly heterogeneous. Their resources differ both in terms of quantity and resource type. Regarding the quantity of resources, we distinguished two groups of actors: those with access to more resources and those with access to fewer resources. The hierarchical cluster analysis for these two sets of actors showed that their access to different types of resources varies (Fig. 6).

Within the set of actors who have access to fewer resources, we identified two groups: (a) actors who have access to more physical and human resources than natural resources, and (b) actors who have access to more natural resources than physical and human resources.

Within the set of actors who have access to more resources, we again have two groups: (c) actors who have access to more physical resources than natural and human resources; and (d) actors who have access to more natural and human resources than physical resources.

Actors from different sectors and levels compose these groups. Group a is composed of actors with fewer resources overall and specific access to physical resources; it comprises private (2) and public (6) actors from the village (3), district (4) and national (1) levels. They are local associations and state representatives.

Group b is composed of actors with fewer resources overall and specific access to natural resources; it comprises private (6) and public (6) actors mostly from the village (10). They are farmers, cash crops intermediaries, and local associations.

Group c is composed of actors with more resources overall and

Actors with fewer resources

Actors with more resources

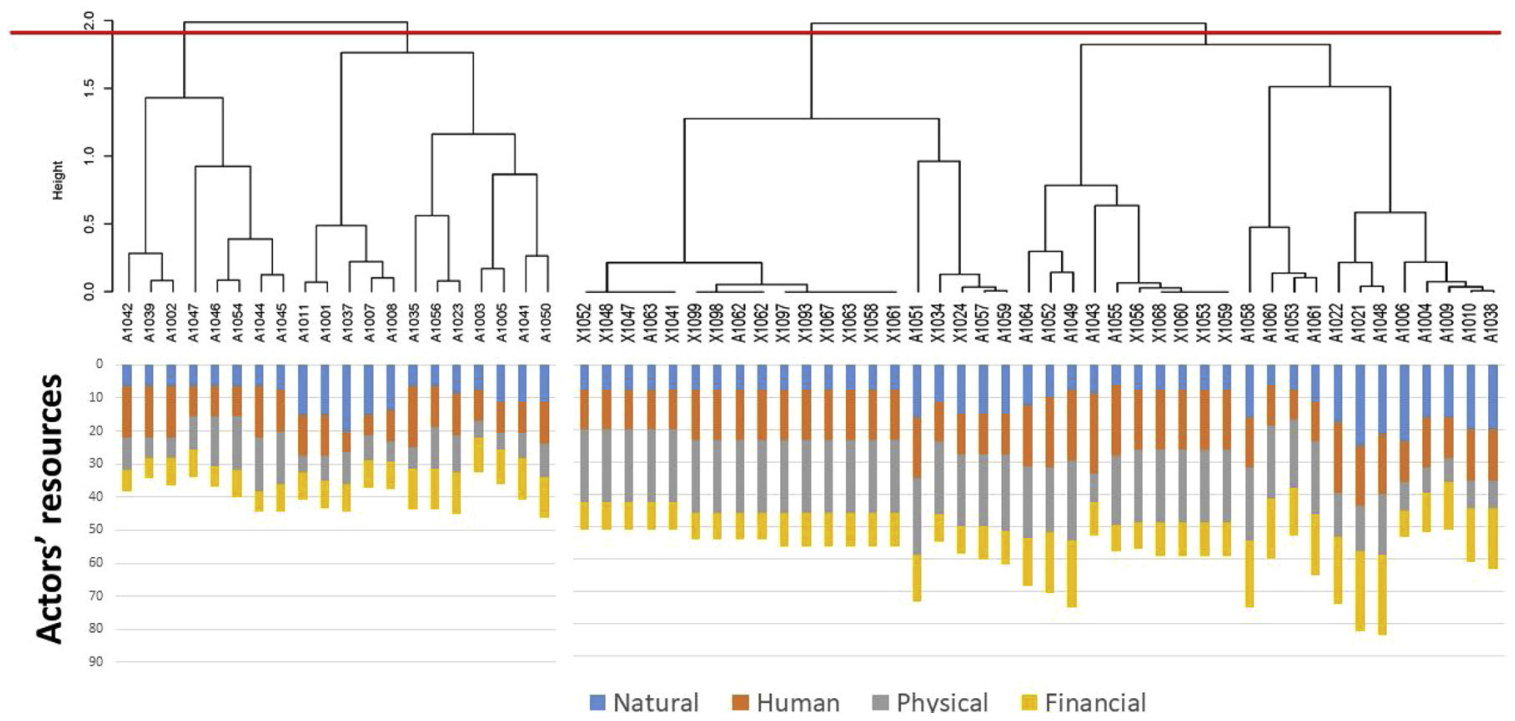

Fig. 6. Actors clustered according to their access to resources and the combinations of these resources. 
specific access to physical resources. It comprises private (3), voluntary (5), and public (12) actors from the district (3), national (6), and international (11) levels. This means that they are mostly international NGOs.

Group d is composed of actors with more resources overall and specific access to natural and human resources. It comprises private (14), voluntary (2), and public (6) actors from the village (7), district (5), national (4), and international (6) levels. They include cash crop intermediaries and collectors, as well as conservation NGOs.

\subsection{Actors' relational profiles}

Based on their three centrality scores, actors can be categorized into five groups (Fig. 7):

Actors with high bridging capacities across sectors and levels and a high degree centrality (top right)

Actors with a high bridging capacity across sectors, a low bridging capacity across levels, and a high degree centrality (bottom right)

(1) Actors with low bridging capacity across sectors, high bridging capacity across levels, and a high degree centrality (top left)

(2) Actors with low bridging capacities across sectors and levels and a high degree centrality (larger nodes at bottom left)

(3) Actors with low bridging capacities across sectors and levels and a low $(<10)$ degree centrality (smaller nodes at bottom left)

Group 1 consists of a single actor only: a cash crop collector at the district level belonging to the private sector. This actor has connections not only to several fellow private-sector actors, but also to actors from the public sector. The actor's activities also connect two different levels: the village and the national level.

Group 2 comprises actors with a high bridging capacity across sectors and a high degree centrality, but a low bridging capacity across levels. It includes five public and three private actors. Among these eight actors, four belong to the village and another four to the district level. Most of the eight actors are government representatives.

Group 3 includes actors with a high bridging capacity across levels and high degree centrality, but a low bridging capacity across sectors. The group is composed of three private actors and one public actor, with two belonging to the district level and two to the national level. These actors interact directly with the other levels via their work in commodity collection and export.

Actors in Group 4 have a high degree centrality, but a low capacity to bridge different sectors and levels. They include five public and ten private actors. Twelve are from the village level, two from the district level, and one from the national level. They are mostly cash crop intermediaries and local associations.

Group 5 has a low degree centrality as well as a low capacity to bridge different sectors and levels. It is composed mostly of public and voluntary actors, along with a few private sector actors, from national and international levels. They are international NGOs and importers.

\subsection{Potential agents of change in telecoupled land governance}

In this section, we detail the results of the principal component analysis of actors based on the three components (aims, resources, and centrality) and their respective variables. On this basis, we then present a typology of potential agents of change.

\subsubsection{Combining aims, resource access, and relational profile}

The results of the principal component analysis show that the two first dimensions ${ }^{1}$ capture $52.1 \%$ of the variance (see Fig. A.1 in

\footnotetext{
${ }^{1}$ The first dimension is explained by the following variables: degree centrality (28.3\%), bridging capacity across levels (15.5\%), bridging capacity across
}

Appendix (in Supplementary material)). On the one hand, actors with predominantly economic aims tend to have a package of assets including degree centrality, bridging capacity across levels, bridging capacity across sectors, and natural, financial, and human resources (lefthand side of Fig. A.1 (in Supplementary material)). On the other hand, actors with predominantly social aims tend to have a low relational profile and little access to resources. Actors with environmental aims tend to have access to physical resources (Fig. A.1 (in Supplementary material)).

\subsubsection{Identifying potential agents of change}

Fig. 8 combines the results from the agency analysis (resource access, $\mathrm{x}$-axis) and the social network analysis (relational profile, $\mathrm{y}$-axis). On this basis, we can distinguish four types of potential agents of change in telecoupled land governance in northeastern Madagascar:

- Actors with a high level of resource access (access to more resources), a high relational profile (higher centrality scores), and mixed or predominantly economic aims

- Actors with a high level of resource access (access to more resources), a low relational profile (lower centrality scores), and mixed or predominantly environmental aims

- Actors with a low level of resource access (access to fewer resources), a high relational profile (high centrality score), and various aims;

- Actors with a low level of resource access (access to fewer resources), a low relational profile (lower centrality scores), and mixed or predominantly social aims.

Two actors with predominantly economic aims top the three components (aims, resources and relational profile). They are private cash crop collectors from the district level. These two actors have a high level of resource access and a high relational profile. Public and voluntary actors with predominantly environmental aims gather at the bottom middle of the diagram, which accommodates actors who have access to considerable physical resources but a low relational profile. Actors with mixed aims mostly spread along the bottom of the diagram, meaning that they have a low relational profile and various levels of resource access.

\subsection{Transformation actions}

Social, economic, and environmental problems like cash-crop-related insecurity, poverty, and deforestation persist in northeastern Madagascar and undermine sustainable development (Challies et al., 2019; Nilsson et al., 2018) and sustainability transformations (Verburg et al., 2015). All of these problems are related to land governance issues. Accordingly, land governance must be transformed - through agents of change. Our results show that actors with different combinations of meanings, means, and social networks are currently governing land in northeastern Madagascar. These actors have social, economic, or environmental aims, or none of the three; they have access to more or fewer resources; and they occupy central or peripheral positions in the telecoupled land governance network. Judging by our definition of an ideal agent of change - an actor with sustainability aims, access to rich and diverse resources, and a central position in the network - our investigated land governance network does not include any such agents of change. None of the actors in the network fulfils these criteria. Accordingly, there is a need for transformation actions aimed at influencing actors and empowering potential agents of change

(footnote continued)

sectors (13.4\%), and natural resources (12.4\%). The following variables contribute to the second dimension: social aims $(28.9 \%)$, physical resources (19.5\%), environmental aims (17.8\%), and human resources (14\%). 


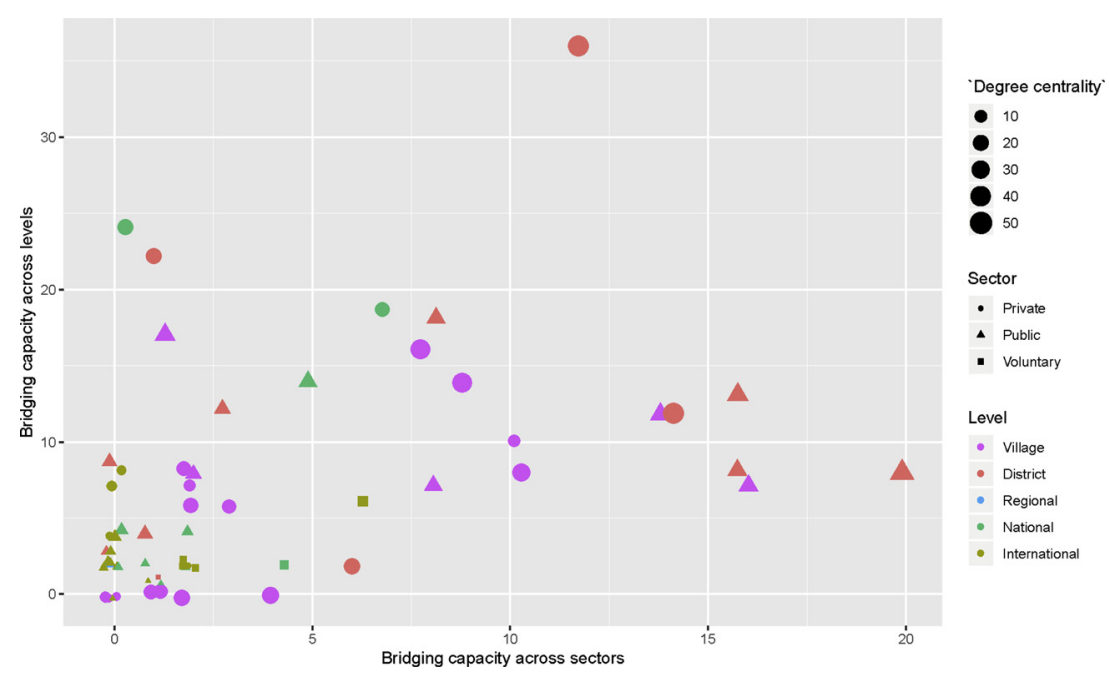

Fig. 7. Weighted scatterplot representing the centrality scores (degree centrality, bridging capacity across sectors, bridging capacity across levels) of actors in telecoupled land governance.

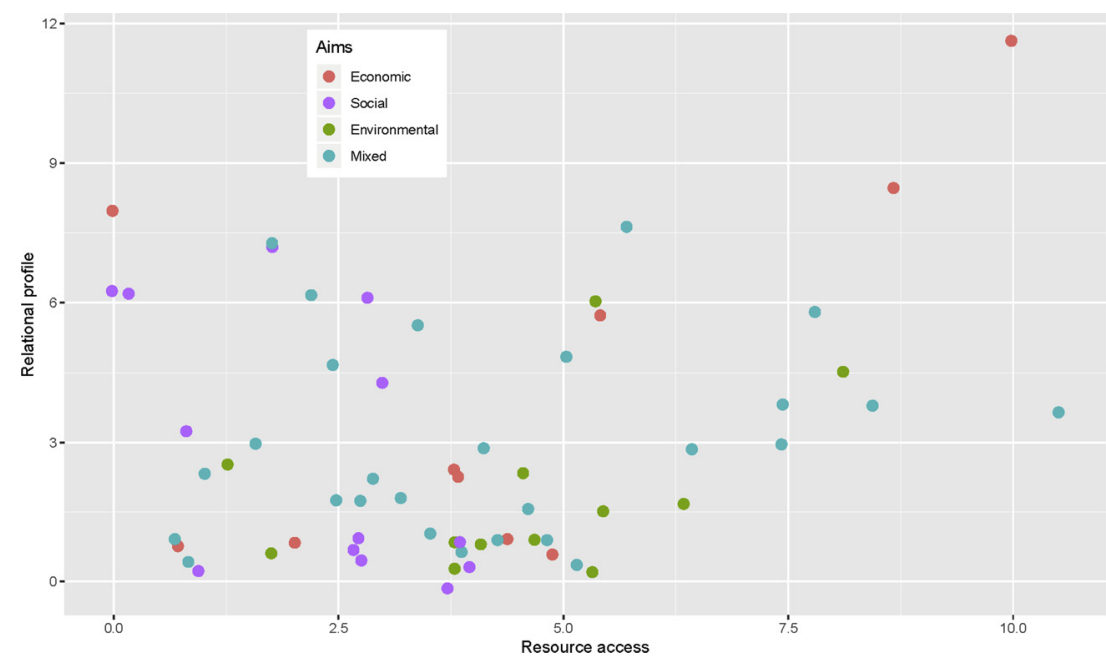

Fig. 8. Typology of actors in the land governance network according to their aims, resources, and relational profile; the x-axis represents the total resource score (resource access) and the y-axis represents the total centrality score (relational profile).

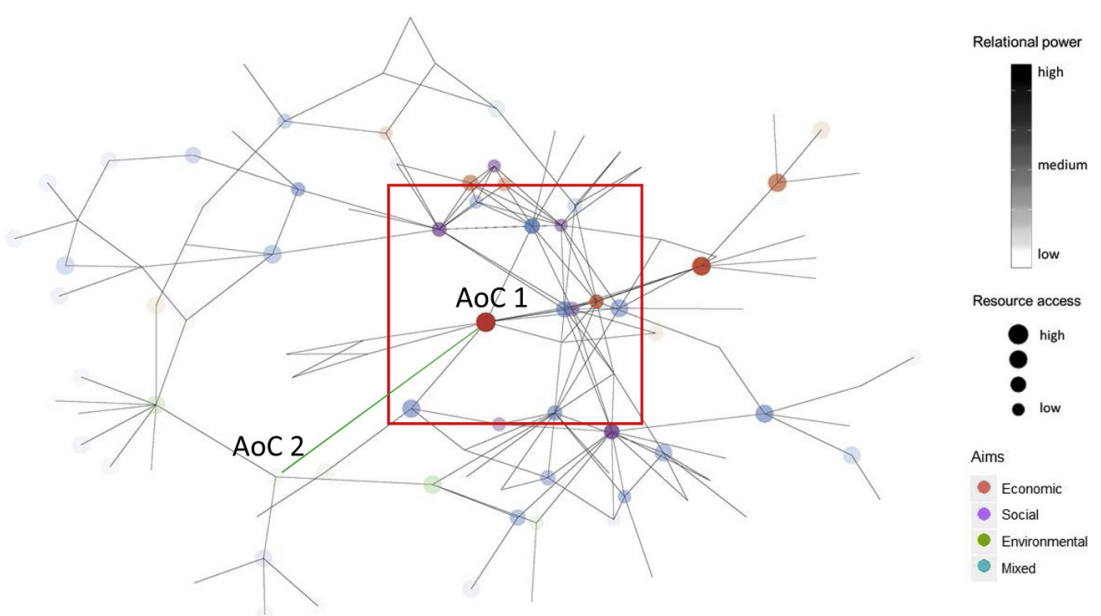

Fig. 9. Network graph of actors linked by flows of goods, money, and information. 
to initiate sustainability transformations. At present, influence is divided among different actors with different aims, and currently empowered actors differ in terms of resource access and relational profiles. To empower agents of change, actors focusing on social, economic, or environmental aims who have a high level of resource access and/or a high relational profile should be connected with each other. This way, they would influence each other through value (or aim) learning (Crona and Parker, 2012; Horcea-Milcu et al., 2019; Moyson et al., 2017; Steyaert and Jiggins, 2007; Westley et al., 2013). In addition, they should be connected with actors who have levels of resource access and relational profiles that are too low for them to successfully achieve their aims (Duygan et al., 2019; Mintrom and Norman, 2009). Once connected, actors will influence and empower each other through value learning and transfer of resources and social networks. They will form a kind of coalition (Aviram et al., 2020) that gathers the required attributes through influence and empowerment and, in addition, fosters adaptive governance (Duygan et al., 2019; Westley et al., 2013,2011).

Our results from the typology graph (Fig. 8) point to two actors, situated at the top right, as the best potential agents of change. They possess a high level of resource access and a high centrality score. However, the fact that their primary aim is narrowly economic, and not per se sustainable, means they are not ideal agents of change for sustainable development or sustainable land governance. However, this could be overcome through targeted transformation actions. These transformation actions could, for example, consist in enhancing the aims of the two actors by linking them with other actors who possess mixed or socially and environmentally focused aims. At the same time, the actors with mixed or socially and environmentally focused aims could benefit from transfer of resources and/or improved social relations. Ideally, new connections would be established between actors belonging to the same land governance network.

Fig. 9 shows the land governance network of our two case study landscapes in northeastern Madagascar. The nodes represent actors involved in the land governance network, with colour codes indicating actors' aims (social, economic, environmental, or mixed), node size indicating their level of resource access (high or low), and node transparency indicating their relational profile (high or low). The lines linking the nodes represent existing flows of goods, money, and information between actors. In this way, Fig. 9 displays existing connections among actors in the network, thereby highlighting possible channels for transformative actions. For example, we might focus on the actor - namely, AoC 1 (refer also to Fig. 8) - who possesses the highest resource access and relational profile as well as predominantly economic aims, and examine the existing connections of this actor. Looking at Fig. 9, AoC 1 is the reddish node at its centre (within red square). Studying its connections, AoC 1 appears to interact with actors possessing mixed aims (blue nodes) as well as predominantly social aims (purple node). Accordingly, we might expect the latter actors' aims to gradually expand or enhance the rather narrow economic aims of AoC 1. AoC 1 is also connected to actors with less access to resources (smaller nodes). AoC 1 could empower these actors by transferring physical resources to them. Finally, AoC 1 is connected to actors with lower relational profiles (more transparent nodes). AoC 1 could empower them in terms of their social network.

Finally, to provide another example, Fig. 9 shows a green arrow connecting AoC 1 and another actor that we will call AoC 2. This connection is recommended, but does not exist yet. AoC 2 has slightly less resource access (smaller node), a considerably lower relational profile (more transparent node), and predominantly environmental aims (green node). Actors with such low relational profiles are usually public or voluntary actors from the national or international level who are active in conservation. The recommended connection between AoC 1 and AoC 2 would enable the two actors to exchange about aims and influence each other on behalf of more sustainable strategies. Moreover, the conservation actors could benefit from the relational profile of private actor AoC 1 in terms of raising awareness of the importance of their work. In practical terms, one transformation action might consist of bringing a cash crop collector together with a conservation agency to align their agendas, incentivized by means of a transfer of funds.

\section{Conclusions}

Agents of change ideally have social, economic, and environmental aims, access to resources they can mobilize to contribute to transformation, and a wide social network they can use to advocate sustainability thinking. The definition or identification of potential agents of change should thus be based on an analysis of actors' agency (aims and resources) and social network (relational profile). Taking into account only one of these attributes would produce misleading results and hamper the intended promotion of sustainability transformations. Mbaru and Barnes (2017) identified key players in ensuring the diffusion of conservation information and initiatives through target populations in Kenya using social network analysis parameters. They considered different centrality metrics of stakeholders who might ensure the facilitation of conservation objectives. An analysis of these actors' agency could complete these authors' study in the event that the identified actors do not match policymakers' strategies or do not have the resources needed to ensure diffusion. To give another example, Lampert and Mohan (2018) considered the strategies Chinese migrants have regarding their migration and settlement in Ghana and Nigeria in order to define their impact on development and social transformation. Considering the social structure in which these actors evolve would help to better grasp their transformation capacity. Agency and social networks are complementary actor attributes and deserve to both be taken into account in the definition and the identification of agents of change. In our case, combining social network analysis and agency analysis enabled us to systematically assess which configurations are associated with potential agents of change in the telecoupled land governance network in northeastern Madagascar.

Contextual factors might influence the definition of agents of change. Our approach to identifying agents of change for sustainability transformations could be applied to any social-ecological system with conservation and development issues and represents an important contribution to sustainability science. We assume that the role of resources and social networks is fairly stable as a factor across contexts. Sustainability transformations can only be achieved if actors have sufficient means (in terms of resources and relational profile) to realize their vision. However, the categorization of aims is likely to vary. The need for actors' awareness of different and competing claims or dimensions led us to our definition of sustainability aims as one of the necessary attributes of an ideal agent of change. In situations where claims do not compete at all, this definition could be adapted. For example, in a context where conservation does not compete with socioeconomic development, one might disregard the environmental dimension and consider only social and economic aims. In other words, the definition of relevant aims depends on the problem definition.

In conclusion, this article combines agency analysis and social network analysis in an innovative way in order to identify potential agents of change. As the results from the principal component analysis show, centrality or relational profile measurements from social network analysis are an important component of this identification, but they need to be combined with analysis of actors' aims and their access to resources. Moreover, the paper contributes to the literature with its analysis of transformation actions that can transform potential agents of change into operational agents of change, such as connecting them to enable influence through learning and empowerment through resource and relational profile transfers. More specifically, it is important to connect actors with strong relational profiles and considerable resource access to actors with strong sustainability aims in order to empower the latter in terms of social networks and resource access and to influence the former's aims towards greater sustainability. Besides, it is relevant to connect actors with aims focusing narrowly on one aim category to 
actors with sustainability or balanced or mixed aims or aims focusing on another aim category. The same holds true for connecting actors with few resources to actors with more resources, and actors with low relational profiles to actors with high relational profiles.

For northeastern Madagascar, our empirical study shows that agents of change do not exist in our case study landscapes' current land governance network. Achieving sustainable land governance in northeastern Madagascar thus requires transferring sustainability values that integrate the economic, environmental, and social dimensions of sustainability (Horcea-Milcu et al., 2019; Norton, 2015) and empowering sustainability advocates to drive sustainability transformations. In order to promote transformations to sustainable development, we need to align agendas among unequal actors and rebalance power among agendas. Aligning agendas means building awareness of competing interests and agreeing on informal and formal institutions such as guidelines, laws, and regulations. Rebalancing power means empowering change agents via their resources and innovating networks through collaborations on complementary agendas and collaborations among sustainability actors. In practical terms, this study shows where to foster transformation to achieve sustainable development in the region. Policymakers could foster collaboration between conservation actors, who focus on environmental aims, and private-sector actors doing cash crop business, who focus on economic aims. Working together, they would become aware of their competing claims on land, and possibly align them. Furthermore, collaboration would enable the weaker of these parties to benefit from the stronger's abundant resources or relational power.

Finally, different aspects of this study could be improved or further developed. Time and financial restrictions during data collection prevented us from surveying all identified actors from the villages to the international levels. In addition, some actors were unresponsive to our queries. This had an impact on the data analysis and on our freedom to present the results of our work afterwards. An example is the choice of measures for the social network analysis: As the actors of our network were largely concentrated at the village and the district levels, betweenness and closeness centralities were highly correlated to degree centralities; this forced us to come up with other measures. Furthermore, the coding of aims turned out to be quite subjective, as it was highly contextual and each actor's specific case was taken into consideration. This should be improved in future similar studies, for example by using several coders and assessing intercoder reliability. In terms of further development, our study could be expanded by looking at how these actors could be led to collaborate and fully use their potential as agents of change to influence each other's agendas and means. An assessment of likely transfers of aims, resources, and social networks, as well as likely collaborations between the different actors would strengthen this study's contribution to making land governance in northeastern Madagascar more sustainable.

\section{CRediT authorship contribution statement}

O. Ravaka Andriamihaja: Conceptualization, Data collection, Data curation, Data analysis, Visualization, Writing - Original draft preparation \& editing. Florence Metz: Conceptualization, Visualization, Writing-review \& editing. Julie G. Zaehringer: Conceptualization, Visualization, Writing-review \& editing. Manuel Fischer: Conceptualization, Writing-review \& editing. Peter Messerli: Conceptualization, Writing-review \& editing.

\section{Declaration of Competing Interest}

None.

\section{Acknowledgments}

This study contributes to the Global Land Programme https://glp. earth. The research was carried out as part of the project titled "Managing telecoupled landscapes for the sustainable provision of ecosystem services and poverty alleviation" supported by the Swiss Programme for Research on Global Issues for Development (r4d programme) funded by the Swiss National Science Foundation (SNSF) and the Swiss Agency for Development and Cooperation (SDC) (Grant No. 152167), and in collaboration with the Department of Forestry and Environment at the School of Agronomy in the University of Antananarivo, Madagascar. We thank all surveyed and interviewed actors for their precious time spent answering our questions. We also thank all the village authorities in the two villages for their cooperation. This work would not have been possible without our main research guide, Paul Clément Harimalala, and all other local guides involved. We thank Marlène Thibault and Anu Lannen for language editing.

\section{Appendix A. Supplementary data}

Supplementary material related to this article can be found, in the online version, at doi:https://doi.org/10.1016/j.landusepol.2020. 104882.

\section{References}

Abson, D.J., Fischer, J., Leventon, J., Newig, J., Schomerus, T., Vilsmaier, U., von Wehrden, H., Abernethy, P., Ives, C.D., Jager, N.W., Lang, D.J., 2017. Leverage points for sustainability transformation. Ambio 46, 30-39.

Andriamihaja, O.R., Metz, F., Zaehringer, J.G., Fischer, M., Messerli, P., 2019. Land competition under telecoupling: distant actors' environmental versus economic claims on land in North-Eastern Madagascar. Sustainability 11, 851.

Aviram, N.F., Cohen, N., Beeri, I., n.d. Wind(ow) of Change: A Systematic Review of Policy Entrepreneurship Characteristics and Strategies. Policy Stud. J. 0.

Barlow, J., Lennox, G.D., Ferreira, J., Berenguer, E., Lees, A.C., Nally, R.M., et al., 2016. Anthropogenic disturbance in tropical forests can double biodiversity loss from deforestation. Nature 535, 144-147.

Bertrand, A., Aubert, S., Montagne, P., Lohanivo, A.C., Razafintsalama, M.H., 2014. Madagascar, politique forestière : Bilan 1990-2013 et propositions. Madag. Conserv. Dev. 9, 20-30.

Blythe, J., Silver, J., Evans, L., Armitage, D., Bennett, N.J., Moore, M.-L., Morrison, T.H., Brown, K., 2018. The dark side of transformation: latent risks in contemporary sustainability discourse. Antipode 50, 1206-1223.

Bodin, Ö, Crona, B.I., 2009. The role of social networks in natural resource governance: what relational patterns make a difference? Glob. Environ. Change 19, 366-374.

Boillat, S., Gerber, J.-D., Oberlack, C., Zaehringer, J.G., Ifejika Speranza, C., Rist, S., 2018. Distant interactions, power, and environmental justice in protected area governance: a telecoupling perspective. Sustainability 10, 3954.

Borgatti, S.P., Mehra, A., Brass, D.J., Labianca, G., 2009. Network analysis in the social sciences. Science 323, 892-895.

Braun, B., 2015. Futures: imagining socioecological transformation-an introduction. Ann. Assoc. Am. Geogr. 105, 239-243.

Brockington, D., Wilkie, D., 2015. Protected areas and poverty. Phil. Trans. R Soc. B 370, 20140271.

Carrasco, L.R., Chan, J., McGrath, F.L., Nghiem, L.T.P., 2017. Biodiversity conservation in a telecoupled world. Ecol. Soc. 22.

Challies, E., Newig, J., Lenschow, A., 2019. Governance for sustainability in telecoupled systems. In: Friis, C., Nielsen, J.Ø. (Eds.), Telecoupling: Exploring Land-Use Change in a Globalised World, Palgrave Studies in Natural Resource Management. Springer International Publishing, Cham, pp. 177-197.

Clarke, G., 2007. Agents of transformation? donors, faith-based organisations and international development. Third World Q. 28, 77-96.

Corbera, E., Busck-Lumholt, L.M., Mempel, F., Rodríguez-Labajos, B., 2019. Environmental justice in telecoupling research. In: Friis, C., Nielsen, J.Ø. (Eds.), Telecoupling: Exploring Land-Use Change in a Globalised World, Palgrave Studies in Natural Resource Management. Springer International Publishing, Cham, pp. 213-232.

Crona, B., Parker, J., 2012. Learning in support of governance: theories, methods, and a framework to assess how bridging organizations contribute to adaptive resource governance. Ecol. Soc. 17.

Dentoni, D., Waddell, S., Waddock, S., 2017. Pathways of transformation in global food and agricultural systems: implications from a large systems change theory perspective. Curr. Opin. Environ. Sustain. 29, 8-13.

Duygan, M., Stauffacher, M., Meylan, G., 2019. A heuristic for conceptualizing and uncovering the determinants of agency in socio-technical transitions. Environ. Innov. Soc. Transit.

Eakin, H., DeFries, R., Kerr, S., Lambin, E.F., Liu, J., Marcotullio, P.J., Messerli, P., Reenberg, A., Rueda, X., Swaffield, S.R., Wicke, B., Zimmerer, K., 2014. Significance 
of Telecoupling for Exploration of Land-use Change.

Fischer, M., Ingold, K., Ivanova, S., 2017. Information exchange under uncertainty: the case of unconventional gas development in the United Kingdom. Land Use Policy 67, 200-211.

Freeman, L.C., 1978. Centrality in social networks conceptual clarification. Soc. Netw. 1, 215-239.

Galaz, V., Gars, J., Moberg, F., Nykvist, B., Repinski, C., 2015. Why ecologists should care about financial markets. Trends Ecol. Evol. 30, 571-580.

Gardner, C.J., Nicoll, M.E., Birkinshaw, C., Harris, A., Lewis, R.E., Rakotomalala, D., Ratsifandrihamanana, A.N., 2018. The rapid expansion of Madagascar's protected area system. Biol. Conserv. 220, 29-36.

Garrett, R., Rueda, X., 2019. Telecoupling and consumption in agri-food systems. In: Friis, C., Nielsen, J.Ø. (Eds.), Telecoupling: Exploring Land-Use Change in a Globalised World, Palgrave Studies in Natural Resource Management. Springer International Publishing, Cham, pp. 115-137.

Godar, J., Gardner, T., 2019. Trade and land-use telecouplings. In: Friis, C., Nielsen, J.Ø. (Eds.), Telecoupling: Exploring Land-Use Change in a Globalised World, Palgrave Studies in Natural Resource Management. Springer International Publishing, Cham, pp. 149-175.

Haberl, H., Kastner, T., Schaffartzik, A., Erb, K.H., 2015. Tracing trade-related telecouplings in the global land-system using the embodied human appropriation of net primary production framework. AGU Fall Meet. Abstr.

Horcea-Milcu, A.-I., Abson, D.J., Apetrei, C.I., Duse, I.A., Freeth, R., Riechers, M., Lam, D.P.M., Dorninger, C., Lang, D.J., 2019. Values in transformational sustainability science: four perspectives for change. Sustain. Sci.

Ingold, K., Driessen, P.P.J., Runhaar, H.A.C., Widmer, A., 2018. On the necessity of connectivity: linking key characteristics of environmental problems with governance modes. J. Environ. Plan. Manag. 0, 1-24.

Isaac, M.E., Matous, P., 2017. Social network ties predict land use diversity and land use change: a case study in Ghana. Reg. Environ. Change 1-11.

Keller, E., 2015. Beyond the Lens of Conservation: Malagasy and Swiss Imaginations of One Another. Berghahn Books.

Lambin, E.F., Meyfroidt, P., 2011. Global land use change, economic globalization, and the looming land scarcity. Proc. Natl. Acad. Sci. 108, 3465-3472.

Lampert, B., Mohan, G., 2018. A transformative presence? Chinese migrants as agents of change in Ghana and Nigeria. In: Giese, K., Marfaing, L. (Eds.), Chinese and African Entrepreneurs: Social Impacts of Interpersonal Encounters. Brill, Leiden, pp. 147-169.

Le, S., Josse, J., Husson, F., n.d. FactoMineR: An R Package for Multivariate Analysis. Journal of Statistical Software 25 (1)

Liu, J., Hull, V., Batistella, M., DeFries, R., Dietz, T., Fu, F., et al., 2013. Framing sustainability in a telecoupled world. Ecol. Soc. 18.

Mbaru, E.K., Barnes, M.L., 2017. Key players in conservation diffusion: using social network analysis to identify critical injection points. Biol. Conserv. 210, 222-232.

Meyfroidt, P., Roy Chowdhury, R., de Bremond, A., Ellis, E.C., Erb, K.-H., Filatova, T. et al., 2018. Middle-range theories of land system change. Glob. Environ. Change 53, 52-67.

Mintrom, M., Norman, P., 2009. Policy entrepreneurship and policy change. Policy Stud. J. $37,649-667$.

Moyson, S., Scholten, P., Weible, C.M., 2017. Policy learning and policy change: theorizing their relations from different perspectives. Policy Soc. 36, 161-177.

Munroe, D.K., Batistella, M., Friis, C., Gasparri, N.I., Lambin, E.F., Liu, J., Meyfroidt, P., Moran, E., Nielsen, J.Ø., 2019. Governing flows in telecoupled land systems. Curr. Opin. Environ. Sustain. 38, 53-59.

Neimark, B., Osterhoudt, S., Alter, H., Gradinar, A., 2019. A New Sustainability Model for Measuring Changes in Power and Access in Global Commodity Chains: Through a Smallholder Lens | Palgrave Communications. [WWW Document]. URLhttps:// www.nature.com/articles/s41599-018-0199-0 (accessed 5.28.19).

Neudert, R., Ganzhorn, J.U., Wätzold, F., 2017. Global benefits and local costs - the dilemma of tropical forest conservation: a review of the situation in Madagascar. Environ. Conserv. 44, 82-96.

Nilsson, M., Chisholm, E., Griggs, D., Howden-Chapman, P., McCollum, D., Messerli, P., Neumann, B., Stevance, A.-S., Visbeck, M., Stafford-Smith, M., 2018. Mapping interactions between the sustainable development goals: lessons learned and ways forward. Sustain. Sci.

Norton, B.G., 2015. Sustainable Values, Sustainable Change: a Guide to Environmental Decision Making.

Papworth, S.K., Nghiem, T.P.L., Chimalakonda, D., Posa, M.R.C., Wijedasa, L.S., Bickford,
D., Carrasco, L.R., 2015. Quantifying the role of online news in linking conservation research to Facebook and Twitter. Conserv. Biol. 29, 825-833.

Pelling, M., 2014. Transformation: a renewed window on development responsibility for risk management. J. Extreme Events 01, 1402003.

Poudyal, M., Jones, J.P.G., Rakotonarivo, O.S., Hockley, N., Gibbons, J.M., Mandimbiniaina, R., Rasoamanana, A., Andrianantenaina, N.S., Ramamonjisoa, B.S., 2018. Who bears the cost of forest conservation? PeerJ 6, e5106.

R Core Team, 2017. R: a Language and Environment for Statistical Computing. R Foundation for Statistical Computing, Vienna, Austria.

Roggema, R.E., Vermeend, T., Van den Dobbelsteen, A.A.J.F., 2012. Incremental change, transition or transformation? Optimising change pathways for climate adaptation in spatial planning. Sustain 4 (10) 2012.

Schneider, F., Kläy, A., Zimmermann, A.B., Buser, T., Ingalls, M., Messerli, P., 2019. How can science support the 2030 Agenda for Sustainable Development? Four tasks to tackle the normative dimension of sustainability. Sustain. Sci.

Seaquist, J.W., Johansson, E.L., Nicholas, K.A., 2014. Architecture of the global land acquisition system: applying the tools of network science to identify key vulnerabilities. Environ. Res. Lett. 9, 114006.

Secretary-General, U.N, 2019. Special Edition of the Sustainable Development Goals Progress Report. [WWW Document]. URL https://sustainabledevelopment.un.org/ hlpf/2019/ (accessed 6.28.19). .

Stevens-Rumann, C.S., Kemp, K.B., Higuera, P.E., Harvey, B.J., Rother, M.T., Donato, D.C., Morgan, P., Veblen, T.T., 2018. Evidence for declining forest resilience to wildfires under climate change. Ecol. Lett. 21, 243-252.

Steyaert, P., Jiggins, J., 2007. Governance of complex environmental situations through social learning: a synthesis of SLIM's lessons for research, policy and practice. Environ. Sci. Policy 10, 575-586.

van Vuuren, D., Nakicenovic, N., Riahi, K., Brew-Hammond, A., Kammen, D., Modi, V., Nilsson, M., Smith, K., 2012. An energy vision: the transformation towards sustainability—interconnected challenges and solutions. Curr. Opin. Environ. Sustain. Open issue $4,18-34$

Verburg, P.H., Crossman, N., Ellis, E.C., Heinimann, A., Hostert, P., Mertz, O., Nagendra, H., Sikor, T., Erb, K.-H., Golubiewski, N., Grau, R., Grove, M., Konaté, S., Meyfroidt, P., Parker, D.C., Chowdhury, R.R., Shibata, H., Thomson, A., Zhen, L., 2015. Land system science and sustainable development of the earth system: a global land project perspective. Anthropocene 12, 29-41.

Waeber, P.O., Wilmé, L., Mercier, J.-R., Camara, C., Ii, P.P.L., 2016. How Effective Have Thirty Years of Internationally Driven Conservation and Development Efforts Been in Madagascar? PLoS One 11, e0161115.

Wallis, A.M., 2006. Sustainability indicators: is there consensus among stakeholders? Int. J. Environ. Sustain. Dev. 5 (3), 287-296.

Wasserman, S., Faust, K., 1994. Social Network Analysis: Methods and Applications, Social Network Analysis: Methods and Applications. Cambridge University Press, New York, NY, US.

Westley, F., Olsson, P., Folke, C., Homer-Dixon, T., Vredenburg, H., Loorbach, D, Thompson, J., Nilsson, M., Lambin, E., Sendzimir, J., Banerjee, B., Galaz, V., van der Leeuw, S., 2011. Tipping toward sustainability: emerging pathways of transformation. AMBIO 40, 762

Westley, F., Tjornbo, O., Schultz, L., Olsson, P., Folke, C., Crona, B., Bodin, Ö., 2013. A theory of transformative agency in linked social-ecological systems. Ecol. Soc. 18.

Wiesmann, U., Ott, C., Ifejika Speranza, C., Kiteme, B., Müller-Böker, U., Messerli, P., Zinsstag, J., 2011. A human actor model as a conceptual orientation in interdisciplinary research for sustainable development. In: Wiesmann, U.M., Hurni, H. (Eds.), Research for Sustainable Development: Foundations, Experiences, and Perspectives. Geographica Bernensia, Bern, pp. 231-256.

Wold, S., Esbensen, K., Geladi, P., 1987. Principal component analysis. Chemom. Intell. Lab. Syst. 2 (1), 37-52.

Zaehringer, J.G., Hett, C., Ramamonjisoa, B., Messerli, P., 2016. Beyond deforestation monitoring in conservation hotspots: analysing landscape mosaic dynamics in northeastern Madagascar. Appl. Geogr. 68, 9-19.

Zaehringer, J.G., Schneider, F., Heinimann, A., Messerli, P., 2019. Co-producing knowledge for sustainable development in telecoupled Land systems. In: Friis, C., Nielsen, J.Ø. (Eds.), Telecoupling: Exploring Land-Use Change in a Globalised World, Palgrave Studies in Natural Resource Management. Springer International Publishing, Cham, pp. 357-381.

Zhu, A., 2018. Hot money, cold beer: navigating the vanilla and rosewood export economies in northeastern Madagascar. Am. Ethnol. 45, 253-267. 